\title{
Monitoring of iron deficiency in calves by determination of serum ferritin in comparison with serum iron: A preliminary study
}

\author{
Jessica Joerling* and Klaus Doll \\ Clinic for Ruminants, Justus Liebig University Giessen, Gießen, Germany
}

\begin{abstract}
Background: Iron deficiency can cause anemia in calves and is, therefore, of economic importance for the cattle industry. Low iron levels are commonly caused by feeding whole milk without the addition of dietary supplements and led to the most frequent cause of anemia in calves. Other reasons for the development of anemia include congenital iron deficiency, malnutrition, bleeding ulcers, or bloodsucking parasites.

Aim: This study compared laboratory parameters that are commonly used to diagnose iron deficiency anemia in calves. Additionally, serum ferritin values were compared amongst calves fed different milk meals.

Methods: For this purpose, blood samples from 40 calves were analyzed for different hematologic parameters as well as the content of copper, glutathione peroxidase, serum iron, and serum ferritin.

Results: Eight calves showed decreased hemoglobin and hematocrit values and a significantly lower number of erythrocytes compared with non-anemic calves. Interestingly, 19 of 40 calves had a low serum iron. Considering their serum ferritin levels, only 14 calves, including six calves with both low iron and low ferritin levels, were classified as iron deficient. No direct correlation between serum ferritin and serum iron was detected. Comparing milk diets, more calves fed milk replacer showed reduced levels of ferritin compared with calves fed whole milk.

Conclusion: Our data indicate that the determination of hemoglobin and serum iron is of limited suitability for the diagnosis of iron deficiency in calves. We suggest that the determination of serum ferritin should be the preferred parameter, since serum iron levels are subject to physiological fluctuation and a deficiency can be caused by inflammation or neoplastic diseases.
\end{abstract}

Keywords: Anemia, Calves, Ferritin, Iron deficiency, Serum iron.

\section{Introduction}

Iron deficiency anemia is a common disease in calves, predominately caused by an undersupply of iron during exclusive feeding of whole milk without the additional administration of dietary supplements (Matrone et al., 1957; Andrews, 2004). Accordingly, iron deficiency most likely results from the low iron content in cow's milk, which is approximately $0.5 \mathrm{mg} / \mathrm{kg}$ in raw milk (Mann et al., 2013). Another possible reason for iron deficiency could be chronic blood loss due to bleeding gastrointestinal ulcers, infestation with bloodsucking parasites (Jain, 1986a), hemorrhagic diseases, or malnutrition (Ramin et al., 2012). Iron deficiency is associated with clinical signs, including reduced growth, loss of appetite, and increased infection rates (Mohri et al., 2010). Iron is an important trace element in mammals and performs several vital functions, such as binding and transporting oxygen as a key component of hemoglobin and myoglobin proteins, mediating electron transport within the cells in the form of cytochromes, and facilitating oxygen enzyme reactions in various tissues (Jain, 1986a). In the event of deficiency, iron depletion occurs in three stages: First, the iron storage in the liver, spleen, and bone marrow decreases parallel to serum ferritin, while the serum iron remains constant.
Second, a subsequent time-shifted lowering of the serum iron level occurs. The third stage is eventually characterized by the development of a hypochromic, microcytic anemia (Johnson, 1990). It was suggested in 1977 that ferritin, with its capability of retaining iron in a nontoxic form, might represent a biomarker protein to monitor dietary supplementation of iron (Miyata et al., 1984; Miyata and Furugouri, 1987). In human medicine, the evaluation of ferritin is a standard procedure to control iron supplementation, since the ferritin level in the circulation is directly proportional to the iron storage of the organism (Daru et al., 2017). In veterinary medicine, it has been shown that ferritin is the more sensitive parameter to detect the onset of iron deficiency in dairy bulls, compared to other blood parameters, such as hemoglobin, hematocrit, or quantity of red blood cells (RBC) (Miyata and Furugouri, 1984). However, in female animals postpartum, ferritin is less well suited for diagnostic purposes because serum ferritin may be elevated due to inflammation in the uterus or udder (Furugouri et al., 1982). To differentiate iron deficiency anemia from similar afflictions, a deficit of other trace minerals, such as selenium or copper should be taken into consideration (National Research Council (U.S.), 2001; Heidarpour Bami et al., 2008; Herdt and 
Hoff, 2011). Selenium deficiency leads to muscular dystrophy (Abutarbush and Radostits, 2003), while a shortage of copper impairs the intestinal absorption of iron. Furthermore, copper is an essential element in hematopoiesis, but before anemia is detectable, reduced growth rates and depigmented fur can be observed (Jain, 1986c). To avoid the side effects of over- and under dosing, any supplementation should be preceded by an exact determination of the trace element status, especially in regard to iron. Therefore, the aim of our study was to compare different laboratory parameters regarding the diagnosis of iron deficiency anemia in calves. In terms of the milk meal, this study aimed to compare serum ferritin levels of calves fed commercial milk replacer against those fed whole milk without additives.

\section{Materials and Methods \\ Animals, feeding and management}

Blood samples were collected by jugular venipuncture of 40 calves from four different dairy farms in Hessen, Germany, which have consulted the cattle health service of the Justus Liebig University in Giessen in the past 2 years. The respective blood samples were collected in serum-separating tubes, tubes containing EDTA (Ethylene-Diamine-Tetra-Acetic acid) and tubes containing lithium-heparin (Kabe, Nürmbrecht, Germany). The period of time between sampling and analysis of blood probes was maximal 2 hours (route from farm to clinic). On farm A, blood samples from 10 Holstein calves were obtained. All calves were female and aged between 2 days and 11 weeks. The calves were kept in three separate groups. Three of them had already been weaned from the milk replacer. One newborn calf was housed in an individual pen, while the remaining calves were housed together. Feeding for all the calves consisted of roughage (hay, silage), concentrated feed (rearing feed consisting of shredded grain) and-if not yet weaned-milk replacer. Neonatal calves did not receive a substitution of trace elements, minerals, or vitamins. On farm B, samples of twelve female and two male calves (Holstein and Fleckvieh cattle) were drawn. Calves were aged between 1 day and 9 weeks. Until the age of 2 weeks, calves were fed - dependent from age - up to 81 of whole milk without additives per day and were then switched to milk replacer. Furthermore, roughage (hay) and concentrated feed (rearing feed consisting of peas, wheat, and barley) were offered. Postnatally, all the calves were administered an oral paste with iron and selenium as well as vitamins A, $\mathrm{D}_{3}$, and E. On farm C, two of the six sampled Holstein calves were male. The calves were between 8 days and 12 -week old. The two male calves, 8 -day old, were fed 61 of whole milk without additives per day. The older calves received 81 of whole milk without additives, roughage (silage) and concentrated feed containing maize and grain. In neonatal calves, selenium was administered parenterally. On farm $\mathrm{D}$, calves were between one and 9-week old, and nine out of ten calves (Holstein and Fleckvieh cattle) were male. Four calves that were younger than 2 weeks received 61 of whole milk without additives per day. The older calves were fed eight liters whole milk without additives as well as roughage (hay and silage) and rearing feed (maize meal, shredded grain). On this farm, no trace elements, minerals, or vitamins were supplemented. Farms B and $\mathrm{C}$ had a history of anemia (low $\mathrm{Hb}$ and/or $\mathrm{Ht}$ ) in calves, while on farm $\mathrm{A}$ and $\mathrm{D}$, hematological parameters did not indicate the presence of anemia. Across farms the serum ferritin concentration of all the calves fed whole milk was compared with calves fed commercial milk replacer.

\section{Blood parameters}

Red blood cells (reference range 5-10 T/1) and white blood cells (reference range 4-10 G/l) were counted using the cell counter pocH-100 iV Diff (Sysmex, Norderstedt, Germany). To achieve best possible lab results, gold standards for the measurement of $\mathrm{Ht}$ and $\mathrm{Hb}$ were used. Therefore, the $\mathrm{Ht}$ (reference range $0.28-0.38 \mathrm{~L} / \mathrm{l}$ ) was measured after centrifugation (Haematokrit 210; Hettich, Kirchlengern, Germany). $\mathrm{Hb}$ (reference range $5.6-8.7 \mathrm{mmol} / \mathrm{L}$, Test kit S8430; Labor und Technik Lehmann GmbH, Berlin, Germany) was measured via hemiglobincyanide measurement. This method is recommended by the International Council for Standardization in Haematology. The spectrophotometric absorbance of hemiglobincyanide was measured at $540 \mathrm{~nm}$ (Eppendorf photometer PCP 6121, Eppendorf, Hamburg, Germany). Serum copper (reference range 9.4-15.7 mmol/L, Test kit LT-Cu 0106; Labor und Technik Lehmann $\mathrm{GmbH}$ ), serum iron (reference range $14.5-25 \mathrm{mmol} / \mathrm{L}$, Test kit LTSI 0100; Labor und Technik Lehmann $\mathrm{GmbH}$ ) and glutathione peroxidase in heparinized whole blood (GPx, reference range $>250 \mathrm{U} / \mathrm{g} \mathrm{Hb}$, Test kit RS504; Randox Laboratories GmbH, Krefeld, Germany) were measured photometrically at the respective specific wavelengths recommended by the manufacturer. All parameters were measured in duplicate. MCV (mean corpuscular volume, reference range 27-36.1 $\mathrm{fL}$ ), $\mathrm{MCH}$ (mean corpuscular hemoglobin, reference range $0.66-0.84 \mathrm{fmol}$ ), and $\mathrm{MCHC}$ (mean corpuscular hemoglobin concentration, reference range 20.2-24.18 $\mathrm{mmol} / \mathrm{L}$ ) were calculated after the determination of $\mathrm{Hb}$, $\mathrm{Ht}$, and RBC. Serum was separated from whole blood via centrifugation (10 minutes, $1,500 \times \mathrm{g})$ and stored at $-20^{\circ} \mathrm{C}$ until use. Serum ferritin (reference range $>15$ $\mu \mathrm{g} / \mathrm{l}$ ) was determined by use of a bovine Ferritin ELISA (Biozol, Eching, Germany). Briefly, the sample was added to the buffer in a microtiter plate precoated with polyclonal rabbit anti-Ferritin heavy chain antibodies and was subsequently incubated with a ferritin-HRP conjugate (horseradish peroxidase). After five washing steps, wells were incubated with two substrates for 
the HRP enzyme, which indicated the presence of a positive reaction by a blue color change. The final addition of the stop reagent turned the solution yellow. The results were read photometrically at 450 $\mathrm{nm}$ with an ELISA plate reader (Infinite F50, Tecan, Crailsheim, Germany). The intensity of the color was inversely proportional to the ferritin concentration. All the samples and controls were analyzed in duplicate as recommended by the manufacturer. For evaluation, the arithmetic means were taken. Reference values for cattle were not given by the manufacturer. During pilot test (data not shown) the reactivity of the anti-Ferritin antibody was tested with bovine patients in the Clinic for Ruminants.

\section{Statistics and data analysis}

Statistical data analysis was performed using Fisher's exact test as well as a correlation analysis (BMDP Statistical Software, Cork, Ireland).

\section{Results}

Within the total of 40 calves, eight calves were identified as anemic with low values of $\mathrm{Ht}(<0.28 \mathrm{~L} / \mathrm{L})$ and $\mathrm{Hb}(<5.6 \mathrm{mmol} / \mathrm{L})$ although the erythrocytes were in the normal range (5-10 T/L) (Mohri et al., 2007; Rosenberger et al., 2012) or even slightly elevated in five calves (a dehydration was clinically ruled out). However, the RBC count of the eight anemic calves was $6.91 \mathrm{~T} / \mathrm{L}$ on average, which is significantly lower than the average of $9.31 \mathrm{~T} / \mathrm{L}$ of the 32 non-anemic calves. Between the RBC count on one hand and hematocrit and hemoglobin values on the other hand, significant correlations were achieved ( $p$-values of 0.001 each), i. e., higher amount of RBCs was higher values for $\mathrm{Hb}$ and $\mathrm{Ht}$.

Measuring leucocytes revealed in four of 40 calves a leukocytosis $(>10 \mathrm{G} / \mathrm{L})$, which was manifested with clinical signs in two cases (bronchopneumonia). Of the four calves, one was anemic, two had a low serum iron concentration and two had a serum ferritin concentration $<15 \mu \mathrm{g} / \mathrm{L}$.

In our study, we compared the hemoglobin concentration measured by the cell counter pocH100 iV (SLS-method, Sodium-Lauryl-Sulfate) with values taken from the photometric measurement of hemiglobincyanide. We noticed that hemoglobin concentrations assessed via cell counter (SLS-method) were on average $0.5 \mathrm{mmol} / \mathrm{L}$ lower in 39 of 40 calves than values achieved with the cyanide method.

Nineteen calves showed a serum iron concentration of $<14.5 \mu \mathrm{mol} / \mathrm{L}$ (Moritz et al., 2014). Six of these calves were considered anemic due to decreased $\mathrm{Hb}$ and $\mathrm{Ht}$ values. Furthermore, four non-anemic calves had a combined deficiency of iron $(<14.5 \mu \mathrm{mol} / \mathrm{L})$ and copper $(<9.4 \mu \mathrm{mol} / \mathrm{L})$ (Moritz et al., 2014). Notably, the analysis of the cut-off serum ferritin concentration $(<15 \mu \mathrm{g} / \mathrm{L})$ (Watanabe et al., 1998) revealed that 14 out of 40 calves were considered susceptible to develop iron deficiency anemia. Of the 14 calves with reduced serum ferritin levels $(<15 \mu \mathrm{g} / \mathrm{L})$, six calves had decreased serum iron levels as well but none of those calves were anemic. On the other hand, there were eight calves with serum ferritin concentrations of $>30$ $\mu \mathrm{g} / \mathrm{L}$ (Fig. 1). Three of them were neonates, while the other five calves were between 1 to 4 weeks of age and were fed whole milk only.

No calf had a decline in the erythrocyte index MCV $(<27 \mathrm{fL})$, i.e., no microcytic anemia was detectable. The low $\mathrm{MCH}(<0.66 \mathrm{fmol})$ of four calves was hinting towards a hypochromic anemia. Two of those four calves had low $\mathrm{Hb}$ and $\mathrm{Ht}$ values as well as a low serum iron concentration. Another calf had a normal $\mathrm{Hb}$ and $\mathrm{Ht}$, and a serum ferritin concentration $<15 \mu \mathrm{g} / \mathrm{L}$. The fourth calf showed no other hematologic deviations. Twelve calves showed low MCHC $(<20.2 \mathrm{mmol} / \mathrm{L})$, which could be indicative for iron deficiency anemia. Seven of those calves had signs of anemia (low $\mathrm{Hb}$ and $\mathrm{Ht}$ ), too. Furthermore, five of the seven anemic calves showed a decreased serum iron, but no calf revealed a low level of serum ferritin. In two of the twelve calves with lowered MCHC, a lowered serum iron was measured without any other hematological deviations. Of all the 12 calves, two displayed a low serum ferritin concentration but no other deviations.

Significant correlations were evident between serum iron and $\mathrm{Hb}$ ( $p$-value 0.042 , positively correlated) and between serum ferritin and $\mathrm{Hb}$ ( $p$-value 0.013, negatively correlated). Similar correlations were found between serum ferritin and RBC ( $p$-value 0.003 , negatively correlated) as well as between serum iron and $\mathrm{RBC}$ ( $p$-value 0.017, positively correlated). Furthermore, serum ferritin was positively correlated with MCV ( $p$-value 0.011) and negatively with MCHC ( $p$-value 0.001). On the other hand, Ht was positively correlated with serum iron concentration ( $p$-value 0.018$)$. In calves with copper $(<9.4 \mu \mathrm{moL} / \mathrm{L}$, $n=11)$ or selenium $(<250 \mathrm{U} / \mathrm{g} \mathrm{Hb}, n=11)$ deficiency

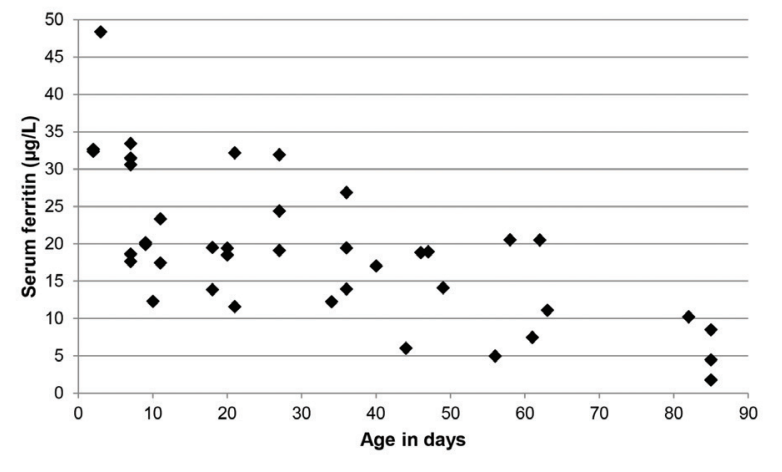

Fig. 1. Age-dependent serum ferritin concentration in 40 calves (Holstein and Fleckvieh cattle) from one to 90 days of age. Each dot represents the measured serum ferritin value of a single calf. 


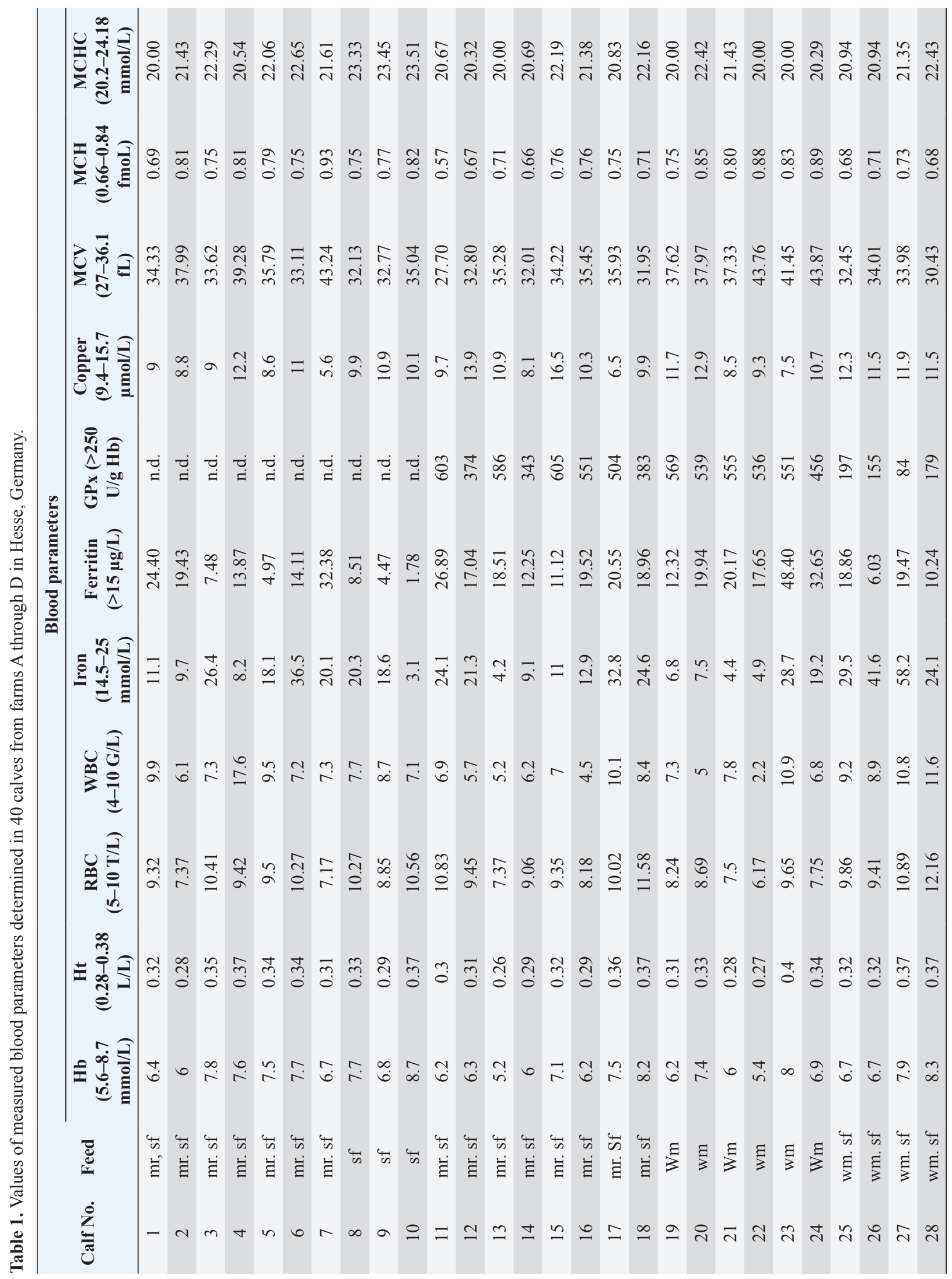




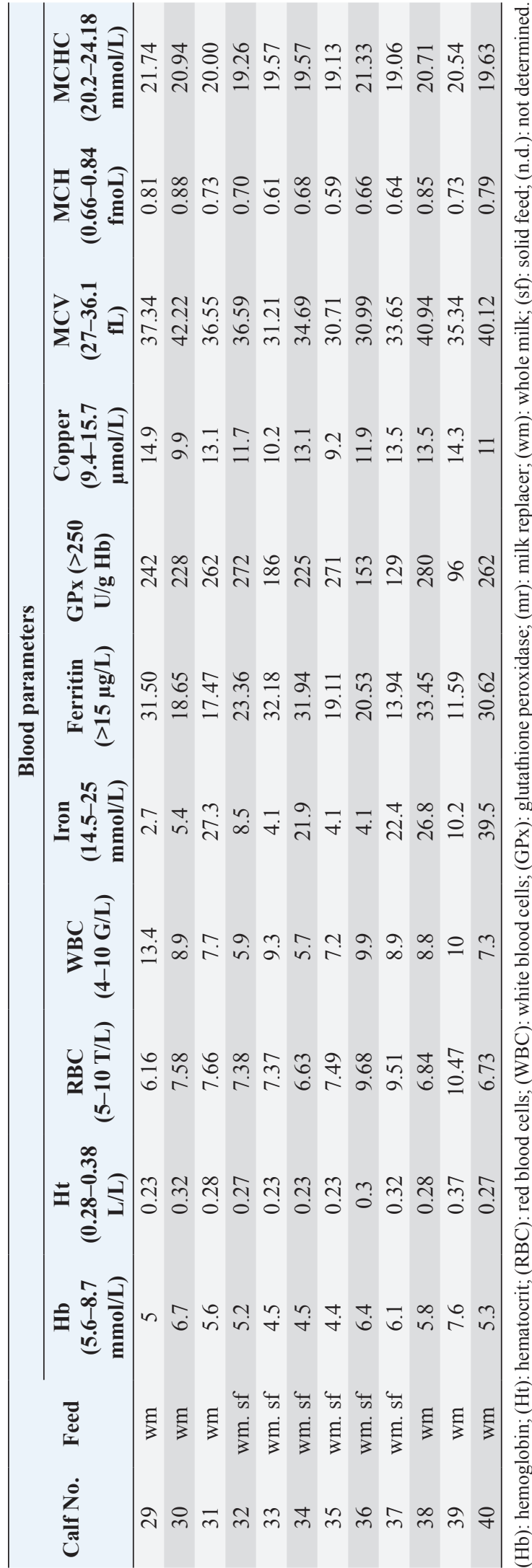

combined with mild abnormalities concerning other blood parameters, no significant relations were found ( $p$-value $>0.05)$. On farm D, $50 \%$ of calves $(n=10)$ had a selenium deficiency and were not supplemented postnatal. On farm C, calves were parenterally supplemented with selenium, but all calves $(n=6)$ displayed low GPx values. On farm B, all calves $(n=$ 12) were orally supplemented with selenium and no calf had a low GPx value. Blood parameters are presented in Table 1.

Comparing the composition of the milk meal, 5 of 22 calves that were fed with whole milk without additives showed a decreased serum ferritin concentrations of $<15 \mu \mathrm{g} / \mathrm{L}$. Seven calves fed whole milk were anemic (low $\mathrm{Hb}$ and $\mathrm{Ht}$ ). Of 18 calves receiving milk replacer (three calves were already weaned), nine calves showed serum ferritin concentrations $<15 \mu \mathrm{g} / \mathrm{L}$. In addition, four of these nine calves had decreased serum iron concentrations. Overall, eight calves fed milk replacer had a low serum iron concentration. Only one of the 18 calves was anemic (low $\mathrm{Hb}$ and $\mathrm{Ht}$ ).

\section{Discussion}

Anemia is a widely distributed clinical manifestation of various disorders (iron deficiency, bloodsucking parasites, and bleeding ulcers) occurring in calves. Thus, it was rather unexpected that none of the 40 calves evaluated in this study showed a decreased RBC count. Since the RBC counting with the cell counter pocH-100 iV is very reliable, an incorrect estimation of this value can be ruled out (Deprez et al., 2009; Riond et al., 2011). Hence, the diagnosis of anemia was based on lowered $\mathrm{Hb}$ and $\mathrm{Ht}$ values as well as erythrocyte indices. Nevertheless, a higher amount of RBCs was significantly correlated with elevated levels of $\mathrm{Hb}$ and $\mathrm{Ht}(p$-value $<0.001)$. However, hematological parameters, such as $\mathrm{Hb}, \mathrm{Ht}$, and $\mathrm{RBC}$, generally show an age-dependent trend, being higher at birth and declining over the next 6 months (Jain, 1986b). A possible explanation for the normal amount of erythrocytes in the anemic calves is the low MCV (reference range 27-36 fL) compared with adult cattle (reference range 46-65 fL). The low MCV can be compensated through the higher amount of RBCs. On the bottom line calves and adult cattle possess the same concentration of hemoglobin (reference range 5.6-8.7 $\mathrm{mmol} / \mathrm{L}$ ) (Brun-Hansen et al., 2006).

Typically, iron deficiency anemia is a microcytotic, hypochromic anemia. Of 19 calves in our study with a low serum iron concentration, seven calves had a low MCHC and two calves had a low MCH in addition. Interestingly no calf had a low MCV. The discrepancy between erythrocyte indices and serum iron is unsatisfactory for practioners trying to identify the cause for anemia.

According to German animal welfare rules ("TierschutzNutztierhaltungs-Verordnung"), hemoglobin blood 
levels must be higher than $6 \mathrm{mmol} / \mathrm{L}$ to represent a sufficient iron supply. In Europe (Directive 2008/119/ EC), an average hemoglobin blood level $\geq 4.5 \mathrm{mmol} / \mathrm{L}$ is required to verify a sufficient iron content in animal feed. If milk replacer was fed on the farms, a minimum iron content of $100 \mathrm{mg} / \mathrm{kg}$ was specified by the manufacturer. When feeding raw milk, no mineral additives were used by the farmer. The concentrated feed contained an average of $360 \mathrm{mg} / \mathrm{kg}$ iron. Roughage (hay, silage) iron content depends on the cutting and contamination with soil (hay $2017 \varnothing 459$ $\mathrm{mg} / \mathrm{kg}$ dry matter, data from the "Landeskuratorium der Erzeugerringe für tierische Veredlung in Bayern e. V.”). On farms A, B, and C, the average blood hemoglobin values were $7.29,6.61$, and $6.88 \mathrm{mmol} / \mathrm{L}$, respectively. On farm D, on the other hand, the average value of blood hemoglobin was $5.54 \mathrm{mmol} / \mathrm{L}$. Based on the recommendations given in the $\mathrm{EC}$ directive, there were no calves on any of the farms suspected of being irondeficient. Referring to the fact that $\mathrm{Hb}$ values from the cell counter were $0.5 \mathrm{mmol} / \mathrm{L}$ lower than the cyanide method, the method for screening the $\mathrm{Hb}$ concentration of calves should be scrutinized critically.

Due to the fact that Hesse is considered a selenium deficiency region a substitution of this element should take place. In our study, the oral supplementation was more sufficient than a parenteral administration of selenium. However, the best way to achieve an optimal selenium supply of the calf is the fetomaternal circulation. Consequently, the mineral feed of dry cows should be monitored.

Due to the low iron content of raw milk and the minimum content of $30 \mathrm{mg} / \mathrm{kg}$ iron in milk replacer (dry matter $88 \%$ ) prescribed by law for calves under $70 \mathrm{~kg}$, we wanted to compare the influence of different milk meals on the level of serum ferritin. A big advantage of raw milk is the persistent transfer of immunoglobulins, while the possibility to transfer pathogens is likely as well. This disadvantage can be bypassed with feeding milk replacer. Furthermore, it has a constant composition, but may have a lower digestibility due to plant components. Although whole milk (without additives) is considered as a risk factor in the development of iron deficiency, in our study, serum ferritin concentration $<15 \mu \mathrm{g} / \mathrm{L}$ were more often found in calves fed with commercially available milk replacer. Nine of eighteen calves $(50 \%)$ fed with or already weaned from milk replacer had a decreased serum ferritin concentration. However, only 5 of 22 calves $(23 \%)$ fed whole milk had noticeably low serum ferritin values. Based on our data, the development of iron deficiency anemia is a multifactorial process and cannot be explained solely by low iron content in dairy milk. Moreover, there are no conclusive reasons explaining the low iron content in dairy milk, but hypothetically, this could be considered a protection mechanism against bacterial infections in the calf, since iron is essential in bacterial development (Messenger and Barclay, 1983). Furthermore, evolutionarily, low iron levels might be sufficient in wild ruminants since they grow up more slowly compared to domesticated cattle. However, both hypotheses need further verification.

Some difficulties exist in finding applicable reference values for serum ferritin because of varying recommendations for bovines in the literature as well as different test systems (two-site immunoradiometric assay (IMRA) or enzyme-linked immunosorbent assay (ELISA)). In addition, there are differences in the serum ferritin concentrations regarding the age or sex of the animals. On average, the serum ferritin concentration of dairy cows in late gestation as well as in adult dairy bulls is $35 \mu \mathrm{g} / \mathrm{L}$ (two-site IRMA), while in dairy bulls up to 23 months of age, the mean value is $13 \mu \mathrm{g} / \mathrm{L}$ (two-site IRMA) (Furugouri et al., 1982; Miyata and Furugouri, 1984). Calves up to 13 weeks of age that were fed whole milk without supplement of iron exhibited serum ferritin levels of $10 \mu \mathrm{g} / \mathrm{L}$ without having disorders regarding any hematologic parameters. At week 13 of the experiment, serum ferritin levels of the untreated as well as the treated calves were on the same level of approximately $10 \mu \mathrm{g} / \mathrm{L}$ (two-site IRMA) (Miyata et al., 1984). In another study, serum ferritin levels in male calves were constant at approximately $10-18 \mu \mathrm{g} / \mathrm{L}$, which confirms the previously mentioned study (twosite IRMA) (Furugouri, 1984). In calves of five to six months of age, serum ferritin levels of approximately $15 \mu \mathrm{g} / \mathrm{L}$ were measured (ELISA) (Watanabe et al., 1998). On the other hand, serum ferritin levels of 26 $\mu \mathrm{g} / \mathrm{L}$ were quoted as appropriate for 2-month-old calves (Immunoturbidimetric assay) (Atyabi et al., 2006). Finally, Japanese scientists reported that serum ferritin levels were $14 \pm 4 \mu \mathrm{g} / \mathrm{L}$ in 7-day-old calves and rose to $33 \pm 10 \mu \mathrm{g} / \mathrm{L} 4$ weeks later followed by a drop to $12 \pm 0.4 \mu \mathrm{g} / \mathrm{L}$ in 3-month-old calves (two-site IRMA) (Miyata and Furugouri, 1987). Based on this data, we determined the cut-off serum ferritin value of $<15 \mu \mathrm{g} / \mathrm{L}$. Calves up to 3 months of age with lower serum ferritin values are considered to be insufficient supplied with iron. However, the measurement of serum ferritin in 3-day-old calves does not seem to be suitable to evaluate the quality of the milk replacer, as calves of this age show physiologically high levels of serum ferritin (Furugouri et al., 1983; Miyata et al., 1984). This phenomenon was confirmed by our study but a reasonable explanation was not determined.

In human medicine, it is well known that serum iron levels vary with food intake and show changes throughout the day as well. Furthermore, acute and chronic inflammations lead to decreased serum iron levels, while hemolysis through faulty blood sampling or blood parasites also results in increased serum iron levels (Lothar Thomas, 2000). For the diagnosis of an iron deficiency, the determination of serum ferritin levels is favored in human medicine because it detects 
$90 \%$ of iron deficient patients versus $42 \%$ of patients when serum iron content was used as the parameter (Burns et al., 1990). In our study, 14 calves had a low serum ferritin concentration $<15 \mu \mathrm{g} / \mathrm{L}$ with no other hematological deviations of $\mathrm{Hb}$ or Ht. This supports the fact that serum ferritin is the best parameter to discover an anemia before it becomes clinically manifested.

To the best of our knowledge, there are no laboratories in Germany that offer serum ferritin examinations in cattle. Therefore, to correctly diagnose anemia, practitioners are reliant on hematologic parameters, serum iron determination and clinical signs. However, a decreased serum iron concentration can also result from chronic infections, neoplasia, or absorptive disorders (Jain, 1986a). In contrast, serum ferritin is increased in cases of disease or neoplasia, while a decreased serum ferritin level is a highly reliable indicator for an iron deficiency. Hence, serum ferritin diagnosis will help to differentiate iron deficiency from (infectious) diseases and prevent unnecessary iron supplementation since this may promote bacterial growth (Cross et al., 2015). In cases of disease or inflammation, iron is shifted from the blood circulation into storage (liver and spleen), leading subsequently to iron deficient erythropoiesis (Pieracci and Barie, 2005). In addition, injection of iron into rats and mice increased the virulence of several pathogens. For example, sublethal doses of Escherichia coli became lethal when administered to rats together with iron in the form of hemoglobin (Pieracci and Barie, 2005). In contrast, a medically necessary administration of iron in the postnatal period is beneficial in leading to increased weight gain and growth (Atyabi et al., 2006; Mohri et al., 2010). Nevertheless, the supply of other trace minerals and vitamins is necessary for the appropriate growth of the calf, especially in farms with a history of anemia. However, iron supplementation should be avoided if anemia is accompanied by clinical signs such as bronchopneumonia or inflammation of the umbilical region. Optimally, serum ferritin levels of cows should be controlled during gestation, and iron should be supplemented if necessary, to provide the fetus with a sufficient amount of iron.

In summary, our data indicates that serum iron and $\mathrm{Hb}$ values do not represent reliable markers for iron deficiency. Serum ferritin, on the other hand, seems to be more reliable because low levels do not provoke differential diagnosis. Furthermore, the correlation between serum ferritin and serum iron was not significant ( $p$-value 0.678). Another advantage of measuring serum ferritin is that iron depletion can be detected during its onset, which allows for early intervention and prevents the manifestation of anemia. This study is only preliminary and was intended to draw attention to the need of validating serum ferritin as a new parameter for the diagnosis of iron deficiency anemia in calves. Further trials are needed to validate reference values for dairy cows, bulls, calves at different ages and perchance small ruminants. Additional trials with experimental iron-overload and iron-shortage will be necessary, too.

\section{Acknowledgments}

The authors would like to thank B. Neeb-Sonntag for excellent technical assistance as well as the participating farmers. Furthermore, the authors also would like to thank Dr. Failing and his colleagues (biomathematics and data handling) for their help with the statistical evaluation of the study. In addition, the authors also would like to thank Prof. Dr. Ewers and Dr. Herbst (Institute of Hygiene and Infectious Diseases of Animals) for the provision of the workplace.

\section{Conflict of interest}

The Authors declare that there is no conflict of interest.

\section{References}

Abutarbush, S.M. and Radostits, O.M. 2003. Congenital nutritional muscular dystrophy in a beef calf. Can. Vet. J. 44, 738-739.

Andrews, A.H. 2004. Other calf problems. In Bovine medicine. Eds., Andrews, A.H. Oxford, UK: Blackwell Science, pp: 249-264.

Atyabi, N., Gharagozloo, F. and Nassiri, S.M. 2006. The necessity of iron supplementation for normal development of commercially reared suckling calves. Comp. Clin. Pathol. 15, 165-168.

Brun-Hansen, H.C., Kampen, A.H. and Lund, A. 2006. Hematologic values in calves during the first 6 months of life. Vet. Clin. Pathol. 35, 182-187.

Burns, E.R., Goldberg, S.N., Lawrence, C. and Wenz, B. 1990. Clinical utility of serum tests for iron deficiency in hospitalized patients. Am. J. Clin. Pathol. 93, 240-245.

Cross, J.H., Bradbury, R.S., Fulford, A.J., Jallow, A.T., Wegmüller, R., Prentice, A.M. and Cerami, C. 2015. Oral iron acutely elevates bacterial growth in human serum. Sci. Rep. 5, 16670.

Daru, J., Colman, K., Stanworth, S.J., La Salle, B. de, Wood, E.M. and Pasricha, S.-R. 2017. Serum ferritin as an indicator of iron status: what do we need to know? Am. J. Clin. Nutr. 106, 1634S-1639S.

Deprez, P., Bauwens, C., van Schandevijl, K., Lefère, L., Nollet, H., De Clercq, D. and van Loon, G. 2009. Evaluation of the pocH-100iV DIFF hematology analyzer for use in horses and cattle. Vlaams Diergeneeskd. Tijdschr. 78, 105-109.

Furugouri, K. 1984. Ferritin, iron and total iron-binding capacity of the serum from Holstein young steers in prolonged undernutrition. Nihon Juigaku Zasshi 46, 859-865.

Furugouri, K., Miyata, Y. and Shijimaya, K. 1982. Ferritin in blood serum of dairy cows. J. Dairy Sci. 65, 1529-1534. 
Furugouri, K., Miyata, Y., Shijimaya, K. and Narasaki, N. 1983. Developmental changes in serum ferritin of piglets. J. Anim. Sci. 57, 960-965.

Heidarpour Bami, M., Mohri, M., Seifi, H.A. and Alavi Tabatabaee, A.A. 2008. Effects of parenteral supply of iron and copper on hematology, weight gain, and health in neonatal dairy calves. Vet. Res. Commun. $32,553-561$.

Herdt, T.H. and Hoff, B. 2011. The use of blood analysis to evaluate trace mineral status in ruminant livestock. Vet. Clin. North Am. Food Anim. Pract. 27, 255-283.

Jain, N.C. 1986a. Blood loss or hemorrhagic anemias. In Schalm's veterinary hematology. Ed., Jain, N.C. Philadelphia, PA: Lea \& Febiger, pp: 577-588.

Jain, N.C. 1986b. Cattle: normal hematology with comments on response to disease. In Schalm's veterinary hematology. Ed., Jain, N.C. Philadelphia, PA: Lea \& Febiger, pp: 178-207.

Jain, N.C. 1986c. Depression or hypoproliferative anemias. In Schalm's veterinary hematology. Ed., Jain, N.C. Philadelphia, PA: Lea \& Febiger, pp: 655-675.

Johnson, M.A. 1990. Iron. Nutrition monitoring and nutrition status assessment. J. Nutr. 120, 14861491.

Lothar Thomas. 2000. Eisen. In Labor und diagnose. Ed., Thomas, L. Indikation und Bewertung von Laborbefunden für die medizinische Diagnostik. Frankfurt am Main, Germany: TH-BooksVerlagsgesellschaft mbH, pp: 280-282.

Mann, G.R., Duncan, S.E., Knowlton, K.F., Dietrich, A.D. and O'Keefe, S.F. 2013. Effects of mineral content of bovine drinking water: does iron content affect milk quality? J. Dairy Sci. 96, 7478-7489.

Matrone, G., Conley, C., Wise, G.H. and Waugh, R.K. 1957. A study of iron and copper requirements of dairy calves. J. Dairy Sci. 40, 1437-1447.

Messenger, A.J.M. and Barclay, R. 1983. Bacteria, iron and pathogenicity. Biochem. Educ. 11, 54-63.

Miyata, Y. and Furugouri, K. 1984. Serum ferritin concentration of dairy bulls: determinations by radioimmunoassay and enzyme immunoassay. Nihon Juigaku Zasshi 46, 783-789.
Miyata, Y. and Furugouri, K. 1987. The relationship between serum ferritin concentration and tissue non-heme iron or tissue ferritin in dairy cattle. Nihon Juigaku Zasshi 49, 1157-1159.

Miyata, Y., Furugouri, K. and Shijimaya, K. 1984. Developmental changes in serum ferritin concentration of dairy calves. J. Dairy Sci. 67, 1256-1263.

Mohri, M., Poorsina, S. and Sedaghat, R. 2010. Effects of parenteral supply of iron on RBC parameters, performance, and health in neonatal dairy calves. Biol. Trace Elem. Res. 136, 33-39.

Mohri, M., Sharifi, K. and Eidi, S. 2007. Hematology and serum biochemistry of Holstein dairy calves: age related changes and comparison with blood composition in adults. Res. Vet. Sci. 83, 30-39.

Moritz, A., Kraft, W. and Dürr, U.M. (Eds.). 2014. Klinische Labordiagnostik in der Tiermedizin. Der neue Kraft/Dürr; mit 286 Tabellen. Stuttgart, Germany: Schattauer.

National Research Council (U.S.). 2001. Nutrient requirements of dairy cattle. Chapter 6 Minerals. Washington, D.C: National Academy Press.

Pieracci, F.M. and Barie, P.S. 2005. Iron and the risk of infection. Surg. Infect. 6(Suppl 1), S41-S46.

Ramin, A.G., Asri-Rezaei, S., Paya, K., Eftekhari, Z., Jelodary, M., Akbari, H. and Ramin, S. 2012. Evalutation of anemia in calves up to 4 months of age in Holstein dairy herds. J. Fac. Vet. Med. Istanbul Univ. 7, 87-92.

Riond, B., Weissenbacher, S., Hofmann-Lehmann, R. and Lutz, H. 2011. Performance evaluation of the Sysmex pocH-100iV Diff hematology analyzer for analysis of canine, feline, equine, and bovine blood. Vet. Clin. Pathol. 40, 484-495.

Rosenberger, G., Dirksen, G., Gründer, H.-D. and Stöber, M. 2012. Die klinische Untersuchung des Rindes. Stuttgart, Germany: Enke.

Watanabe, K., Ozawa, M., Ochiai, H., Kamohara, H., Iijima, N., Negita, H., Orino, K. and Yamamoto, S. 1998. Changes in iron and ferritin in anemic calves infected with Theileria sergenti. J. Vet. Med. Sci. 60, 943-947. 